Eslok", is rather queer. If I understand it aright, the intention is sensible enough: to use a parable about an imaginary tribe, the Koltinnopinnu to make a point about the conservative role of traditional ritual in preserving ancient wisdom vital for group survival. But the imaginary legend is dragged out with almost Tolkienian attention to gratuitous detail, including learned footnotes on fine points of the fictitious language of the imaginary Koltinnopinnuo (plurals are formed by adding " $o$ "). I was left with the feeling that I must be missing the point of the story, since I couldn't see the symbolic (or anagrammatic?) significance of these details. Well, if it comes to that, maybe I missed the point of the whole book: there has to be some explanation for my disappointment with it.

Richard Dawkins is University Lecturer in Animal Behaviour at Oxford University, and a Fellow of New College.

\title{
Surprising structures of nucleic acids
}

\section{C.W. Hilbers}

Nucleic Acid Geometry and Dynamics. Edited by R.H. Sarma. Pp.424.(Pergamon: 1980.) Hbk £25, \$55; pbk £11, \$24.50.

IN molecular biology nucleic acids are probably the most discussed of all biological macromolecules. Yet, until the early 1970s, information about the structure these molecules can adopt was mainly based upon resuIts from X-ray diffraction experiments on DNA or RNA fibres. During the past decade the situation has rapidly changed. Several events have contributed to this development. Investigators have been able to crystallize the relatively short transfer RNA and determine its structure to atomic resolution. In addition, newly developed organic synthetic methods have permitted the preparation of well-defined fragments of RNA and DNA, so that single-crystal analysis of these oligonucleotides can be performed, and techniques (NMR, T-jump) for the high-resolution study of the structure and dynamics of nucleic acids in solution have become available.

All of these developments have led to surprising results, outstanding among which is the finding that nucleic acids possess a conformational flexibility that can give rise to structures far more complex than the simple double helix.

Some of the excitement pervading the field is reflected in this book. It is a collection of 16 review chapters by different authors in which the structure and dynamics of nucleic acids are discussed in great detail. The first chapter introduces the nomenclature of nucleic acids, and is followed by a discussion of the way in which structural information can be deduced from NMR measurements and a description of the basics of single-crystal $\mathrm{X}$-ray diffraction techniques as applied to nucleic acids. It is somewhat confusing that although different systems of nomenclature are in current use for nucleic acids and are employed throughout the book, only one is presented in the first chapter. Also, one would have preferred the scaling of the NMR spectra to be given in ppm instead of in $\mathrm{Hz}$.
In the following chapters the basic theme of the book unfolds. Sarma describes the spatial configurations of different forms of DNA, and Seeman gives an account of the crystal structures obtained for oligonucleotides. Lerman's proposal in 1961 that aminoacridine dyes bind to DNA by intercalation between stacked bases has now been verified at atomic resolution for a number of planar dyes intercalated in dinucleotides. Accounts of progress in this area are presented by Sobell and by Berman and Neidle. Rich and his co-workers relate the conformational changes in the sugar phosphate backbone of RNA and DNA fragments, introduced by the intercalation of planar dyes, to the changes occurring in the backbone of tRNA resulting from the intercalation of a base between two consecutive bases.

The intercalation of dyes is taken further by Patel, by Krugh et al. and by Crothers et al. who discuss the information obtained on this subject from solution studies. Fluctuations in nucleic acid structure as monitored by NMR, ESR and tritium and deuterium exchange techniques are covered by Kallenbach and co-workers and by Lerman and co-workers. Finally, theoretical aspects of the structure, flexibility and accessible surface areas are dealt with in the three chapters by Broyde and Hingerty, Olson, and Alden and Kim.

The book is recommended to anyone involved in structural studies of nucleic acids. It contains a wealth of information, written by experts and illustrated with beautifully coloured molecular models many of which were drawn by Irving Geiss. It is not complete, however, in that it does not contain a chapter devoted to the structure and dynamics of tRNA. A potential buyer should also be aware that a large part of the material has already appeared in Stereodynamics of Molecular Systems, edited by R.H. Sarma and published by Pergamon.

C.W. Hilbers is Professor of Physical Chemistry at the University of Nijmegen, The Netherlands.

\section{Stuck on bacteria}

\section{N. Sharon}

Bacterial Adherence. Receptors and Recognition, Series B, Vol.6. Edited by E.H. Beachey. Pp.466. (Chapman and Hall/Methuen Inc.: 1980.) £27.50, \$69.95.

IT is a truism that in order to inhabit or infect a susceptible host, bacteria must be able to "stick" to the tissue surfaces of the host. Surprisingly enough, until the early 1970s little attention was paid to the problem of bacterial adherence to cell surfaces, its molecular mechanism and possible role in host-parasite interactions. The recent explosion of activity in this area may be ascribed, at least in part, to the current intense interest in receptors on cell surfaces, and in their role in intercellular recognition. No wonder that the first treatise on bacterial adherence appears as part of the series on "Receptors and Recognition'.

The 14 chapters in the book are all written by experts active in the field, including several of the pioneers who for some years worked almost alone on bacterial adherence. Notable among them are J.P. Duguid from the University of Dundee and R.J. Gibbons from Boston. The first contribution, by I. Ofek and E.H. Beachey, is an excellent overview of the field. In the subsequent 11 chapters, emphasis is either on adhesion to different surfaces (mucosal, dental or of plants, for example), on the adhesive properties of specific organisms (Enterobacteriaceae, Vibrio, Neisseria, for example), or the binding properties of bacterial appendages (fimbriae or pili) and surface polymers (lipoteichoic acid). This loose organization is probably a reflection of the dearth of knowledge of the basic mechanisms involved in adherence. One of the two concluding chapters deals with recognition systems between eukaryotic cells, a topic of relevance to the prokaryote-eukaryote system of bacterial adherence, and the other with prospects for prevention of the association of harmful bacteria with most mucosal surfaces.

From reading the book it is evident that the adherence of many bacteria to epithelial cells is mediated by complementary molecules - adhesins on the bacteria which react with receptors on the cells in a lock and key manner. In the case of Escherichia coli and other Enterobacteriaceae, the adhesins are lectin-like molecules in the form of fimbriae that can bind reversibly to sugar residues (predominantly D-mannose) on the surface of the epithelial cells, whereas certain mycoplasmas appear to bind in a similar manner to sialic acid residues. Streptococci, on the other hand, appear to bind to cells via their surface lipoteichoic acid. Much remains, however, to be learned about the nature of the adhesins on other bacteria and about the receptors on the tissues, none of which 